\title{
Compared to what? Effects of categorization on hedonic contrast
}

\author{
DEBRA A. ZELLNER \\ Montclair State University, Upper Montclair, New Jersey \\ ELIZABETH A. ROHM \\ Arbor Incorporated, Media, Pennsylvania \\ TERRI L. BASSETTI \\ Washington State University, Pullman, Washington \\ and \\ SCOTT PARKER \\ American University, Washington, D.C.
}

\begin{abstract}
Test stimuli are rated less "good" following very good context stimuli than when presented either alone or following neutral context stimuli. This diminution in rating is called hedonic contrast. In two experiments, the degree of hedonic contrast depended on how subjects were instructed to categorize context and test stimuli. Contrast was substantially attenuated if context and test stimuli were said to belong to different categories. The effect was demonstrated for beverages (Experiment 1) and birds (Experiment 2). Stimuli's hedonic ratings were far less affected by other stimuli declared to belong to a different category than by stimuli declared to belong to a common category.
\end{abstract}

Psychophysical studies of how the judged intensity of a sensory stimulus is influenced by the intensities of other stimuli in the experiment (e.g., Conner, Land, \& Booth, 1987, taste; Frederiksen, 1975, loudness and brightness; Pol, Hijman, Baare, \& van Ree, 1998, smell) usually find contrast - the movement of the judgment of the test stimulus in the direction away from the intensities of the context stimuli. So, for example, Conner et al.'s subjects rated the sweetnesses of two moderately sweet lime drinks in two conditions-one in which their sugar concentrations were the highest of the five drinks presented and a second in which their concentrations were the lowest of the five drinks presented. The two drinks received higher sweetness ratings in the first condition (when they were the sweetest ones) than in the second (when they were the least sweet ones). Wundt (1894, p. 119) attributed contrast to his law of relativity: "Wherever there occurs a quantitative apprehension of sensations, whether as regards intensity or degree of quantity, the individual sensation is estimated by the relation in which it stands to other sensations of the same sense modality." Wundt did

Portions of this work have been presented to the International Society for Psychophysics. The authors thank Paul Rozin for complaining to D.A.Z. that her tendency to categorize all foods together prevented her from enjoying many of them. We thank Åke Hellström for insightful comments at several years' poster sessions. Correspondence concerning this article should be addressed to D. A. Zellner, Department of Psychology, Montclair State University, Upper Montclair, NJ 07043 (e-mail: zellnerd@mail.montclair.edu). not regard his law as restricted to sensory intensity, but to be "applicablein every case where the intensity of a mental process is quantitatively apprehended and compared with that of others."

Researchers studying social cognition (social comparison and social judgment) have also investigated context effects. Among them are J. Brown, Novick, Lord, and Richards (1992); Herr (1986); Manis, Nelson, and Shedler (1988); Martin, Seta, and Crelia (1990); Pelham and Wachsmuth (1995); and Stapel, Koomen, and van der Pligt (1997). Their results have been a mixture of findings of contrast and assimilation (the movement of the judgment of the test stimulus toward ratings of the context stimuli). One instance of assimilation occurred in Herr's Experiment 1. Subjects were primed with the names of famous people who had been judged either moderately hostile or moderately nonhostile. They then read a description of the behavior of a target person ("Donald") who could plausibly be regarded as hostile or nonhostile, and rated his behavior on an 11-point scale. Subjects primed with the moderately hostile names rated Donald as having been more hostile than did subjects primed with the moderately nonhostile names. Thus the ratings of Donald were assimilated to ratings appropriate to the contextual priming names.

Stapel (Stapel et al., 1997; Stapel \& Winkielman, 1998) has provided a rather convincing explanation for the varied findings in the social cognition literature. He suggests that in studies finding assimilation, the context information is used as an interpretation frame. In these studies, 
the test stimulus to be judged is ambiguous on the attribute to be judged and the context information has to be accessible to the subject and applicable to the stimulus to be judged. So, for example, if the actions of a person to be judged are ambiguous (she might be unfriendly or she might be shy and friendly), she will be judged friendly if the context information makes the subject think "shy," and unfriendly if the context calls unfriendliness to mind.

But in studies finding contrast, Stapel suggests, the context information serves as a comparison standard against which the test stimulus is assessed. This is, of course, what happens in the psychophysical studies, and it is what Wundt's (1894) law of relativity referred to.

In order that comparisons occur between context and test stimuli in any realm, the stimuli must be sufficiently similar. This seems to be critical to obtaining a context effect in the psychophysical literature (Bevan \& Pritchard, 1963; Coren \& Miller, 1974). Probably the first and bestknown demonstration that the test stimuli and context stimuli had to resemble each other is that of D. R. Brown (1953). His subjects judged the heaviness of brass cylinders painted with black lacquer when the heaviest weight (the anchor) was either another brass cylinder or a tray. Contrast was reduced when the anchor was the tray (and thus dissimilar to the judged weights) rather than another cylinder (and thus similar to the judged weights). Contrast was even further reduced when subjects were told only to lift the tray but not to judge its heaviness. In this condition, subjects reported that they did not consider the tray a part of the experiment and disregarded its heaviness.

Thus, perceptual similarity of two stimuli involves not only physical similarity but also whether we view them as members of a single category (Coren \& Enns, 1993). The similarity of the context and test stimuli can be affected by instruction as Stapel and Koomen (1997) showed using the Ebbinghaus illusion. The Ebbinghaus illusion is most commonly demonstrated by having a central circle of fixed diameter surrounded by a ring of larger or smaller circles; the central circle appears larger when small circles surround it and smaller when large circles surround it. One of Stapel and Koomen's experiments used faces instead of circles. Faces were identified as belonging to either students or lawyers; thus, students or lawyers could be surrounded by either students or lawyers. When center and surrounding stimuli matched (i.e., all lawyers or all students), size contrast (measured by subjects' attempted reproductions of stimulus widths) exceeded that when they did not match (students surrounded lawyers, or vice versa). Thus instructing subjects how to categorize stimuli can affect perceptual contrast.

Categorization also appears to affect context effects in social judgment. For example, J. Brown et al. (1992) found that female subjects rated themselves more attractive after looking at a target photo of an unattractive female than after looking at a photo of an attractive female. There was no effect when females looked at pictures of attractive or unattractive males, presumably because they considered males to belong to a category different from females. (See also Stapel et al., 1997.)
The effect of instructionally induced categories on social judgments was investigated by Stapel and Winkielman (1998). They studied the influence of categorization on the friendliness/hostility judgments concerning an ambiguously friendly/hostile human (Donald, following Herr, 1986). Subjects first read a description of an ape named Ralph. Ralph was described as either friendly or hostile and was categorized as either an animal or almost human. When Ralph was categorized as almost human (essentially the same category as Donald), Donald was rated more friendly when Ralph was described as hostile than he was when Ralph was described as friendly. However when Ralph was categorized as an animal (different category), then Donald was rated less friendly when Ralph was hostile than he was when Ralph was friendly. So when the context and test stimuli were in the same category, contrast occurred. Assimilation occurred when the stimuli were in different categories, something never seen with sensory stimuli in the psychophysical literature-as Stapel and Winkielman point out.

However, Wanke, Bless, and Igou (2001) found quite different effects of instructionally induced categories with evaluative judgments of objects that were described but not presented. When their subjects were made to consider an excellent toaster (described in an advertisement) as belonging to the same category (brand) as a mediocre one, the mediocre one was thought better than it was when their common brand categorization was not emphasized. Only when subjects were not induced to see the mediocre and excellent toasters as belonging to the same category did contrast occur. This effect is the opposite of that seen in Stapel and Winkielman (1998).

In the present experiments, we investigated how instructions to categorize contextual stimuli affect hedonic judgments. These experiments on hedonic context effects resemble psychophysical context studies in two ways. First, we used physical stimuli rather than verbal descriptions of people or objects. Second, we presented the context and test stimuli in an integrated sequence. However, the present experiments resemble social judgment studies in that the subjects made evaluative judgments of those stimuli.

Contrast is the usual finding in studies of comparative hedonic judgments. According to Beebe-Center (1932/ 1965, p. 222), Fechner (1898) formulated the general principle of hedonic contrast thus: "That which gives pleasure gives more pleasure the more it enters into contrast with sources of displeasure or of lesser pleasure; and a corresponding proposition holds for that which gives displeasure" (p. 232, attributed to Fechner, 1898). According to Beebe-Center, Fechner believed that his principle of hedonic contrast required that certain conditions be fulfilled, including that "the two factors had to bear a certain resemblance to each other" (pp. 222-223). Joint category membership could contribute to resemblance.

Some studies of hedonic evaluation suggest that using stimuli in different categories produces neither contrast nor assimilation. Harris (1929) first showed that pleasant and unpleasant colors produced hedonic contrast with 
other colors. He then (1932) intermingled colors with pleasant or unpleasant odors in two experiments. He found no reliable effect of the intermingled odors on the ratings of the colors, and he concluded that affective contrast was "not the usual result of intermodal affective stimulation" (p. 298). Although 8 subjects showed no intermodal effects, 2 others showed contrast. One expected contrast to occur (having just read Beebe-Center's work). The other showed no intermodal effects in the first experiment but did in the second. When asked why, he reported that whereas in the first experiment he had regarded the colors and odors as separate, in the second the two kinds of stimuli had coalesced into one group. So when this subject regarded the two types of stimuli as unitary, they influenced one another; when he regarded them as separate, they did not.

Harris's $(1929,1932)$ results differ from those of Stapel and Winkielman (1998), who found assimilation for stimuli from different categories but contrast for stimuli within a single category, and more dramatically from those of Wanke et al. (2001). In the present experiments, we investigate the consequences of instructional manipulation of categorization on hedonic evaluation of physical stimuli-when will there be contrast, when assimilation, and when no effect?

\section{EXPERIMENT 1}

Our subjects rate one set of stimuli preceded by others described as being either from the same or from a different category, or preceded by no others at all. All stimuli are fruit juices - the context stimuli presented at full strength, and the test stimuli presented diluted. Hedonic assimilation will appear as elevated hedonic ratings of the dilute juices in people who have recently drunk fullstrength juices. Hedonic contrast will appear as reduced hedonic ratings of the dilute juices in people who have recently drunk full-strength juices. Such a reduction in hedonic ratings of "poor" beverages that were preceded by "good" versions of the same beverages was found by Kamenetzky (1959).

Our purpose is to investigate whether instructing subjects about the categorization of stimuli can modulate their hedonic contrast. For some subjects, the test stimuli are identified as "fruit juices" (as are the context stimuli); for others, they are identified as "commercial drinks." Thus, in one condition, we tell people that all stimuli are from a common category (fruit juices) whereas in a second condition, we tell people that the less good final beverages come from a different category (commercial drinks). We want to see whether declaring the drinks unrelated reduces hedonic contrast.

\section{Method}

Subjects. Sixty Shippensburg University students participated.

Materials. All stimuli were $20 \mathrm{ml}$ of fluid served in .75-oz Solo PO75 plastic cups at room temperature.

The eight context solutions were two instances each of four Mystic brand juices: Cranberry Punch, Kiwi Strawberry, Orange Ba- nana, and Peach Beach. The two test solutions were Orange Sunrise and Papaya Paradise, diluted with bottled spring water to one third their original strength.

Ratings were made on a bipolar hedonic scale on which +100 represented the most pleasant taste imaginable, -100 represented the most unpleasant taste imaginable, and 0 indicated a taste neither pleasant nor unpleasant.

Procedure. The subjects were randomly assigned to one of four groups. The 20 people in Group 1 were presented with a tray holding 10 cups-the 8 context solutions and the 2 test solutions. They were instructed to drink all 10 fruit juices and rate how much they liked each one. The test solutions were always the last two drunk. The subjects drank and rated the juices at 30 -sec intervals, cleansing their palates with spring water between ratings.

The 20 people in Group 2 were presented with a tray holding 8 cups-the 8 context solutions. They were instructed to drink all 8 fruit juices and rate how much they liked each one. They drank and rated juices at 30 -sec intervals, cleansing their palates with spring water between ratings. They were then asked whether they would be willing to try 2 commercial drinks that were being tested for a company in England. When they agreed to do so (as all did) 2 new cups containing the test solutions were brought from across the room and placed on the tray. They were instructed to rate these solutions as they had the previous 8 .

The 10 people in Group 3 were presented with a tray holding 2 cups-the two test solutions. They were instructed as were the people in Group 1.

The 10 people in Group 4 arrived to see an empty tray. They were told that they would be rating commercial drinks that were being tested for a company in England. Then the 2 cups containing the test solutions were brought from across the room and placed on the tray.

Thus, people in Groups 1 and 2 rated the same beverages-the same 8 context stimuli and the same 2 test stimuli. The labels attached to the two final test stimuli differed for the two groups, putting the context and test stimuli into the same category for Group 1 and into different categories for Group 2. That same difference in labels also separated people in Groups 3 and 4, who rated only the labeled test stimuli.

\section{Results}

For each subject in Groups 1 and 2, we calculated the average rating given to the 8 context solutions. The means of those averages are shown in Table 1. For each subject in Groups 1,2,3, and 4 we calculated the average rating given to the 2 test solutions. The means of those averages are also shown in Table 1.

First, we checked to see that Group 1 and 2 subjects' average ratings of the 8 context juices did not differ. A Mann-Whitney test showed that indeed the two sets of average ratings did not differ significantly (Mann-Whitney $U=171.5,228.5, p>.40)$.

Next, we looked at the average ratings given to the 2 test solutions by subjects in Groups 1,2, 3, and 4. The four groups' subjects' average ratings did differ significantly [Kruskal-Wallis $H(3)=25.9, p<.005$ ]. All but

Table 1

Mean Ratings of Context and Test Solutions for All Four Groups

\begin{tabular}{ccc}
\hline Group & Context Solutions & Test Solutions \\
\hline 1 & +23.1 & -30.4 \\
2 & +29.5 & -12.0 \\
3 & - & +14.1 \\
4 & - & +11.0 \\
\hline
\end{tabular}


one of the six post hoc Mann-Whitney tests revealed significant pairwise differences between groups $(p<.05)$; only control Groups 3 and 4 did not differ from each other $(p>.39)$. The test solutions received negative average ratings from 17 and 12 of the 20 subjects in each of Groups 1 and 2 (the first of which was significantly above $50 \%$ [two-tailed $p<.002$ ], though the second was not) but from only 1 and 2 of the 10 subjects in each of Groups 3 and 4 (the first of which was significantly below 50\% [two-tailed $p<.025$ ], though the second was not).

\section{Discussion}

For both Groups 3 and 4, the average subject rated the test solutions slightly positive in the absence of any context solutions; significantly fewer than half (only 3 of the 20) of the subjects in those groups gave the test solutions negative average ratings. Note also that these groups' ratings did not differ from each other, suggesting that labeling the test solutions as fruit juices or as commercial drinks had little effect on hedonic ratings. Overall, then, our most naive subjects rated these solutions as neutral or slightly positive, irrespective of what they were told about them.

Groups 1 and 2's subjects, however, rated the test solutions significantly lower than did Groups 3 and 4's subjects and usually gave them negative ratings, significantly more than $50 \%$ of Group 1's subjects doing so. This shows that the context solutions induced hedonic contrast, lowering the ratings of the test solutions for Groups 1 and 2 below neutrality.

Our main interest is in the different degrees of hedonic contrast shown by Groups 1 and 2. Although Groups 1 and 2's average ratings of the context solutions differed little, their average ratings of the test solutions differed a lot: Group 1 gave the test solutions lower ratings than did Group 2, and Group 1 subjects rated those solutions below zero more often than did Group 2 subjects.

Thus our calling the test solutions commercial drinks and the context solutions fruit juices reduced the hedonic contrast created by the context solutions. This difference appeared despite the fact that without context solutions (i.e., in Groups 3 and 4), labeling the test solutions as commercial drinks resulted in slightly lower average ratings than did labeling them fruit juices-the reverse of the results on Groups 1 and 2.

In neither Group 1 nor Group 2 do we see assimilation. We see contrast in both groups, and more contrast in Group 1 than in Group 2. So contrast, the result for both groups, was reduced when the context and test solutions were identified as being in separate categories

\section{EXPERIMENT 2}

This experiment extends our inquiry to the visual realm. Our stimuli are pictures of birds: North American birds preceded either by other North American or by extremely pretty tropical birds. If attractiveness ratings of North American birds are particularly low for people who recently saw tropical birds, we will have hedonic contrast; if those ratings are elevated, we will have assimilation. But will our identifying tropical birds as "tropical" and North American birds as "North American" affect the ratings? Can we again reduce hedonic contrast by suggesting that the two sorts of stimuli are unrelated?

\section{Method}

Subjects. Forty-eight Shippensburg University students participated. Sixteen served in each of Groups NN, TN, and CTN (see below).

Materials. Colored pictures of birds cut out of books were pasted on $7 \times 11$ in. white posterboard. Twenty pictures (two sets of 10 each) were of plain-looking North American birds with little color. One set of 10 will be called the test set. Another 10 pictures were of brightly colored tropical birds.

Procedure. The subjects were randomly assigned to three different groups: NN, TN, and CTN (explanations follow).

People in Group NN (North American-North American) were told that they would be rating pictures of birds; they were shown one set of North American birds followed immediately by the other one (the test set).

People in Group TN (Tropical-North American) were also told that they would be rating pictures of birds and were shown the set of tropical birds followed immediately by the test set.

People in Group CTN (Categorized Tropical-North American) were told that they would be rating several distinct categories of stimuli. They were told that the first set they would rate were tropical birds and were shown that set. They were then told that they would rate a set of North American birds and shown the test set.

Thus, people in Group NN rated two sets of North American birds. People in both Groups TN and CTN first rated tropical birds and then North American birds. Although the latter two groups saw the same stimulus sets, their instructions differed. The stimulus sets were declared to be from two separate categories for Group CTN and all from one category for Group TN.

The subjects in all groups rated the attractiveness of each bird on a bipolar hedonic scale on which +100 represented the most attractive bird imaginable, -100 represented the most unattractive bird imaginable, and 0 indicated a bird that was neither attractive nor unattractive. They inspected one picture at a time (stimulus sequences randomized within sets) and announced their ratings.

\section{Results}

First, we checked whether the introduction of the tropical birds altered the relative standing of North American birds in the test set. We wanted to make sure that the groups agreed about which test set birds were more attractive and which were less attractive. For each subject in each group, the subject's attractiveness ratings of the 10 birds in the test set served to rank the 10 birds in attractiveness; these numbers (1-10) are called attractiveness rankings. Thus each bird in the test set got an attractiveness ranking from each subject in a group. We averaged a bird's attractiveness rankings for all subjects in a group to create a group attractiveness hierarchy. Those hierarchies could be compared for different groups, to see whether groups agreed about which of the test set's North American birds were prettier and which were less attractive.

We calculated the Spearman rank-order correlation coefficient $\left(r_{\mathrm{s}}\right)$ for attractiveness rankings for the North 
American test set in each pair of groups. The value of $r_{\mathrm{s}}$ was +.89 for Groups NN and TN, +.99 for Groups NN and CTN, and +.90 for Groups TN and CTN. Thus the relative rated attractivenesses of the 10 test set birds were highly similar for all three groups, irrespective of which set of birds had preceded them.

For each subject in each group, we calculated the average rating assigned to birds in the test set. We sought evidence of hedonic contrast in Group TN-lower average ratings by subjects in Group TN than by subjects in Group NN. The groups' mean ratings were $-6.2(\mathrm{TN})$ and $+23.7(\mathrm{NN})$, and the $\mathrm{NN}$ subjects' average ratings were significantly higher than those for TN subjects (Mann-Whitney $U=42,214, p<.001$ ).

To look for hedonic contrast in Group CTN, we compared ratings of the test set for Groups NN and CTN. The groups' mean ratings were $+13.9(\mathrm{CTN})$ and $+23.7(\mathrm{NN})$. Group NN gave higher ratings than did CTN, but not quite significantly so (Mann-Whitney $U=82,174, .05<$ $p<.10)$. So if there was hedonic contrast in Group CTN, it seems to have been attenuated. (See Table 2).

Because differences in the ratings of the tropical birds by Groups TN and CTN might have contributed to any contrast differences that we found, we checked whether Groups TN and CTN rated the initial set of tropical birds equivalently. The groups' mean ratings were $41.6(\mathrm{TN})$ and $44.5(\mathrm{CTN})$, and there was no significant difference between the groups (Mann-Whitney $U=119.5,136.5$, $p>.70)$. So Groups TN and CTN rated tropical birds similarly (see Table 2). Thus, differences in the subjects' reactions to tropical birds contributed little to any other differences we might find.

Finally, we compared levels of hedonic contrast in Groups TN and CTN directly. For each subject, we subtracted the mean rating for North American birds from the mean for tropical birds to create a personal mean difference (PMD). Larger PMD values indicate greater separation between tropical bird and North American bird attractiveness ratings; that is, PMD increases with hedonic contrast. The mean PMD was 47.8 in Group TN and 30.6 in Group CTN (Mann-Whitney $U=186,70 ; p<$ $.05)$. So there was less hedonic contrast in Group CTN than in Group TN.

\section{Discussion}

Groups NN and TN were both told merely that they would be rating pictures of birds. They differed in that

Table 2

Mean Ratings of the First Set and the Test Set (Second Set) of Birds for the Three Groups

\begin{tabular}{llc}
\hline Group & \multicolumn{1}{c}{ First Set of Birds } & $\begin{array}{c}\text { Test Set of Birds } \\
\text { (North American) }\end{array}$ \\
\hline TN & +41.6 (Tropical) & -6.2 \\
CTN & +44.5 (Tropical) & +13.9 \\
NN & +21.0 (North American) & +23.7 \\
\hline
\end{tabular}

Note-TN, Tropical-North American. CTN, Categorized TropicalNorth American. NN, North American-North American.
Group TN saw tropical birds before the North American test set, whereas NN saw only North American birds. The test set of North American birds got higher ratings from NN than from TN subjects, indicating hedonic contrast in Group TN. Contrast was reduced in Group CTN, who were told that the tropical birds and the test birds were in different categories. Thus, instructions to categorize context and test stimuli as different reduced hedonic contrast in ratings of visual stimuli as they had in ratings of chemical stimuli (Experiment 1).

\section{GENERAL DISCUSSION}

Our results indicate that the degree of hedonic contrast between stimuli depends on whether or not they belong to a common category. Hedonic contrast for stimuli assigned to a common category far exceeded that for the same stimuli assigned to separate categories.

These findings parallel our (Zellner, Kern, \& Parker, 2002) results in a naturalistic study of coffee drinkers and beer drinkers. Coffee drinkers who thought gourmet coffee and everyday coffee were in separate categories rated everyday coffee hedonically positive on average, whereas those who thought them to be in same category rated everyday coffee hedonically negative on average; the two groups did not differ in their ratings of gourmet coffee. The analogous phenomenon occurred for beer drinkers rating specialty and regular beers. Thus, even in naturalistic settings, hedonic contrast is greatest for stimuli within a common category.

These results can be explained as a mere change in verbal response. However, our preferred interpretation is that contrast in hedonic ratings represents perceptual hedonic contrast - that your stereo loudspeakers really do sound less good to you than they did before you heard the state-of-the-art FechnerSonics 2 (unless you regard your budget-priced stereo equipment as a fundamentally different product line from the expensive state-of-the-art gear). Parducci (1995) has indicated that hedonic changes explained by his range-frequency theory reflect actual affective changes. We agree with him.

Among the reasons why we believe that the effect reflects a true change in our subjects' affective responses are the negative ratings given to the test stimuli in the two studies. In particular, in Experiment 2, the mean hedonic rating of the test set was negative for Group TN but positive for Group CTN. That the test stimuli were disliked by the subjects who were not categorizing but were liked by the subjects who were categorizing is noteworthy.

Our findings are consistent with Stapel's thinking (Stapel et al., 1997; Stapel \& Winkielman, 1998). He predicts contrast whenever the context information provides a comparison standard against which the test stimulus is assessed. In our experiments, when the stimuli were from the same category, the context stimuli provided an anchor along the hedonic dimension for other such stimuli and thus provided a standard for compari- 
son. Stapel predicts assimilation when the context provides an interpretation frame, as brand name seems to have done in Wanke et al. (2001).

Our subjects encountered physical stimuli in a sequence that integrated the contextual and the test stimuli. Thus, our procedures were those commonly used in psychophysical experiments on context effects. A psychophysical theory consistent with our results is Parducci's (1995) range-frequency theory. In Parducci's view, stimuli that extend the range of a category cause the ratings of other stimuli in that category to move in a direction away from that of the range-extending stimuli. Parducci's theory shares with Stapel's thinking the prediction of contrast for stimuli in the same category but not for stimuli in separate categories, the opposite of the predictions of Wanke et al. (2001). We think it likely that the small amount of contrast that we observed for stimuli in different categories stemmed from those stimuli's common membership in a superordinate category (fruity drinks in Experiment 1, birds in Experiment 2) and that we would have seen no contrast at all had our stimuli truly been from completely separate categories. This is consistent with Fechner's view. Recall that Fechner thought that a "certain resemblance" between the context and test stimuli was a requirement for the occurrence of contrast. Joint membership in a superordinate category might well contribute to "resemblance" and thus provide a basis for some contrast. Sharing membership in both a subordinate category and a superordinate category, then, should increase resemblance and hence increase contrast. Our instructional control of category membership could, on that view, increase or reduce resemblance (and hence, contrast) but could not eliminate it entirely. (For a related view of resemblance and contrast, see Sarris, 1976.) Resemblance is graded, and its gradations might influence the degree of contrast between stimuli.

\section{REFERENCES}

Beebe-Center, J. G. (1965). The psychology of pleasantness and unpleasantness. New York: Russell \& Russell. (Original work published 1932)

Bevan, W., \& Pritchard, J. F. (1963). The anchor effect and the problem of relevance in the judgment of shape. Journal of General Psychology, 69, 147-161.

BRown, D. R. (1953). Stimulus-similarity and the anchoring of subjective scales. American Journal of Psychology, 66, 199-214.

Brown, J., Novick, N., Lord, K., \& RichardS, J. (1992). When Gulliver travels: Social context, psychological closeness, and self-appraisals. Journal of Personality \& Social Psychology, 62, 717-727.

Conner, M., Land, D., \& Booth, D. (1987). Effect of stimulus range on judgements of sweetness intensity in a lime drink. British Journal of Psychology, 78, 357-364.
Coren, S., \& EnNS, J. T. (1993). Size contrast as a function of conceptual similarity between test and inducers. Perception \& Psychophysics, 54, 579-588.

Coren, S., \& Miller, J. (1974). Size contrast as a function of figural similarity. Perception \& Psychophysics, 16, 355-357.

Fechner, G. T. (1898). Vorschule der Aesthetik II (2nd ed.). Leipzig: Breitkopf \& Härtel.

FREDERIKsEN, J. R. (1975). Two models for psychophysical judgment: Scale invariance with changes in stimulus range. Perception \& Psychophysics, 17, 147-157.

Harris, A. J. (1929). An experiment on affective contrast. American Journal of Psychology, 41, 617-624.

Harris, A. J. (1932). Affective contrast between modalities. American Journal of Psychology, 44, 289-299.

Herr, P. M. (1986). Consequences of priming: Judgment and behavior. Journal of Personality \& Social Psychology, 51, 1106-1115.

KAMENETZKY, J. (1959). Contrast and convergence effects in ratings of foods. Journal of Applied Psychology, 43, 47-52.

Manis, M., Nelson, T. E., \& Shedler, J. (1988). Stereotypes and social judgment: Extremity, assimilation, and contrast. Journal of Personality \& Social Psychology, 55, 28-36.

Martin, L., Seta, J., \& Crelia, R. (1990). Assimilation and contrast as a function of people's willingness and ability to expend effort in forming an impression. Journal of Personality \& Social Psychology, 59, 27-37.

ParducCI, A. (1995). Happiness, pleasure, and judgment: The contextual theory and its applications. Mahwah, NJ: Erlbaum.

Pelham, B. W., \& Wachsmuth, J. O. (1995). The waxing and waning of the social self: Assimilation and contrast in social comparison. Journal of Personality \& Social Psychology, 69, 825-838.

Pol, H. E. H., Hijman, R., BaAre, W. F. C., \& van Ree, J. M. (1998). Effects of context on judgments of odor intensities in humans. Chemical Senses, 23, 131-135.

SARRIS, V. (1976). Effects of stimulus range and anchor value on psychophysical judgment. In H.-G. Geissler \& Y. M. Zaprodin (Eds.), Advances in psychophysics (pp. 253-268). Berlin: VEB Deutscher Verlag der Wissenschaften.

Stapel, D. A., \& Koomen, W. (1997). Social categorization and perceptual judgment of size: When perception is social. Journal of Personality \& Social Psychology, 73, 1177-1190.

Stapel, D. A., Koomen, W., \& VAn der Pligt, J. (1997). Categories of category accessibility: The impact of trait concept versus exemplar priming on person judgments. Journal of Experimental Social Psychology, 33, 47-76.

Stapel, D. A., \& Winkielman, P. (1998). Assimilation and contrast as a function of context-target similarity, distinctness, and dimensional relevance. Personality \& Social Psychology Bulletin, 24, 634-646.

Wanke, M., Bless, H., \& Igou, E. (2001). Next to a star: Paling, shining, or both? Turning interexemplar contrast into interexemplar assimilation. Personality \& Social Psychology Bulletin, 27, 14-29.

WundT, W. (1894). Lectures on human and animal psychology (J. E. Creighton \& E. B. Titchener, Trans.). New York: Macmillan. (Original work published 1892)

Zellner, D., Kern, B., \& Parker, S. (2002). Protection for the good: Subcategorization reduces hedonic contrast. Appetite, 38, 175-180.

(Manuscript received September 28, 2000; revision accepted for publication April 17, 2002.) 